\title{
In memoriam. Orlando Zelaya-Angel's contributions in Superficies y Vacío
}

\author{
M. A. Santana-Aranda \\ Head Editor, Superficies y Vacío, SMCTSM \\ Departamento de Física, CUCEI, Universidad de Guadalajara \\ Guadalajara, Jalisco, 44430, México. \\ (After a year of your departure: November 23rd, 2021)
}

\begin{abstract}
Professor Orlando Zelaya Angel was an outstanding member of the research community on Solid State Physics. He served as President to the Sociedad Mexicana de Ciencia de Superficies y Vacío (SMCSyV; currently Sociedad Mexicana de Ciencia y Tecnología de Superficies y Materiales - SMCTSM), for the period 1995-1996. Professor Zelaya formed many researchers in Mexico, who continue developing research, either in Mexico, in their countries of origin, or abroad. Throughout the evolution of Superficies y Vacío, Professor Zelaya, contributed with sixteen articles on subjects ranging from thin films for optoelectronic applications, through hard coatings and studies on the process for production of Tortillas; covering most of his research areas of interest. Here is a subject-chronological compilation of the abstracts to his articles in Superficies y Vacío, after a year of his departure.
\end{abstract}

\section{II-VI semiconductors and related compounds}

Electrical conductivity, structure and composition of CdSbTe thin films (in Spanish) [1]. CdSbTe thin films were grown using the $\mathrm{r}-\mathrm{f}$ sputtering technique, employing as a target, a CdTe pellet with an area $\mathrm{A}_{o}$ of $5 \mathrm{~cm}^{2}$, on which an $\mathrm{Sb}$ plate was placed, with area $\mathrm{A}_{\mathrm{x}}$, which varied between 0.08 and $1.25 \mathrm{~cm}^{2}$. Auger spectra show that $\mathrm{Sb}$ content increases with $\mathrm{A}_{\mathrm{x}}$, meanwhile the percentages of $\mathrm{Cd}$ and Te decrease. $\mathrm{X}$-ray diffraction shows that for Sb concentration under 20\%, the films grew in a cubic structure, with preferential orientation in the (111) direction. When the Sb concentration increases over $30 \%$, the films are amorphized. Electrical conductivity was measured as a function of temperature in the $25-150{ }^{\circ} \mathrm{C}$ interval.

CdTe thin films grown by radio frequency sputtering under an Ar-N atmosphere (in Spanish) [2]. CdTe thin films grown at room temperature over corning glass substrates employing the radio frequency sputtering ( $R F$ sputtering) technique in Ar gas, show absorption edge shifts to higher energies that depend directly on the introduced amount of $\mathrm{N}_{2}$ in low percentages in the Ar atmosphere. Resistivity and photoreflectance measurements also show an increase of the band gap energy with the increase of $\mathrm{N}_{2}$ in the growth process. X-ray diffraction patterns indicate an amorphous nature of the sample material. Auger analysis shows that nitrogen does not incorporate into the films, however, large amounts of $\mathrm{O}_{2}$ are found, which are greater the higher is the band gap energy of the material.

Thermally stimulated conductivity (TSC) in a polycrystalline CdTe film (in Spanish) [3]. The features of the electric carrier traps are studied using the CTE technique in a polycrystalline CdTe thin film, grown by close space vapor transport (CSVT). By fitting the experimental curves with the Dussel-Bube model, the activation energies of the observed trapping levels are determined.
Growth and characterization of CdS thin films (in Spanish) [4]. By using the CBD (chemical bath deposition) method, polycrystalline cadmium sulfide (CdS) thin films were deposited on glass. Characterization was performed with X-ray diffraction, spectroscopic ellipsometry and transmission electron microscopy. The determined properties were: band gap energy, shielding factors, crystallographic structure and morphology. The results on the optical nature for these films, were compared with those obtained for films grown by vapor phase epitaxy.

Electric percolation in composites: epoxic-planar graphite (in Spanish) [5]. It was studied the electrical percolation process in composites: epoxy-planar graphite type as a function of the concentration of the included phase (x). It was found that the threshold of percolation is present for $\mathrm{x}=47.19 \%$, that is characteristic for a bidimensional system.

Confinement effects on CdTe:O sputtered films prepared at high substrate temperature [6]. Five CdTe:O thin films with a mean thickness of about $200 \mathrm{~nm}$ were grown by a reactive radiofrequency sputtering technique in a controlled $\mathrm{N}-\mathrm{O}-\mathrm{Ar}$ plasma. The substrate temperature was held at $500{ }^{\circ} \mathrm{C}$ during 3 hours of deposition for each sample. The oxygen content in the films was controlled by the gradual amount of nitrogen partial pressure. Structural and optical properties of the grown films were obtained from $\mathrm{x}$-ray diffraction patterns and optical absorption spectra respectively. Samples containing oxygen showed typical diffraction peaks associated with cubic and hexagonal crystalline phases as well as Te oxides. We used the DebyeScherrer formula to measure the crystallite size and we found a nonlinear shift in the absorption band edge, that arises from strong structural changes in the material, as well as a quantum effect for the material with crystal size smaller than the exciton diameter in CdTe. 
MBE growth of CdTe epilayers on $\operatorname{InSb(111)~substrates}$ [7]. We report a study of CdTe layers grown on $\operatorname{InSb}(111)$ substrates by molecular beam epitaxy. CdTe/InSb heterostructures prepared under different conditions were characterized in-situ by reflection high-energy electron diffraction (RHEED) and Auger electron spectroscopy. As ex-situ characterization we used atomic force microscopy (AFM) and Raman spectroscopy. According to the results, an In-Te compound (likely $\mathrm{In}_{2} \mathrm{Te}_{3}$ ) is formed at the interface. The proportions of the In-Te compound and remaining oxides at the interface depend on the substrate preparation, polarity of the (111) substrate, and annealing temperature before growth. The CdTe growth is smoother on the (111)B surface.

Monitoring of the MBE growth processes of CdTe on InSb by laser light scattering [8]. We have studied by Laser Light Scattering (LLS) the oxides surface desorption of InSb substrates, and the subsequent growth of CdTe layers by molecular beam epitaxy (MBE). LLS measurements allowed us to determine the critical temperature before surface degradation of $\mathrm{InSb}$, which is not evidently noticed by reflection high-energy electron diffraction (RHEED). Surface defects appeared on substrates where this temperature was exceeded, as observed by scanning electron microscopy (SEM) and Atomic Force Microscopy (AFM). During the MBE growth of CdTe on InSb, two features were noticed in LLS measurements. First, a decrease in intensity was observed that can be associated to a change in surface roughness at the initial stages of growth. The second feature is an oscillatory behavior, which can be related to interference. A geometrical model of interference in thin films was used to calculate the layer thickness in real time.

Preparation of $\mathrm{Cd}_{1-\mathrm{x}} \mathrm{Mn}_{\mathrm{x}} \mathrm{Te}$ samples by radiofrequency sputtering (in Spanish) [9]. Polycrystalline $\mathrm{Cd}_{1-\mathrm{x}} \mathrm{Mn}_{\mathrm{x}} \mathrm{Te}$ films were grown at room temperature on Corning glass 7059 substrates by radio frequency sputtering from a CdTe-Mn target. Small thin plates of elemental Mn covering small areas were glued onto the target. The optical and structural properties of the films were analyzed as a function of the $\mathrm{Mn}$ concentration. When the manganese is incorporated to CdTe lattice, we find that band gap energy increases to $1.64 \mathrm{eV}$ at $\mathrm{x}=0.03$. We can conclude that it is possible to growth $\mathrm{Cd}_{1-\mathrm{x}} \mathrm{Mn}_{\mathrm{x}} \mathrm{Te}$ ternary compound by radio frequency sputtering using CdTe-Mn target.

Er-doped CdS thin films: electrical characterization [10]. Cadmium sulfide thin films were prepared by chemical bath on glass substrates at $80^{\circ} \mathrm{C}$. CdS was Er-doped during the growth process by adding water-diluted $\mathrm{Er}\left(\mathrm{NO}_{3}\right)_{3} \cdot 3 \mathrm{H}_{2} \mathrm{O}$ to the growing aqueous solution. The relative volume of the doping solution was varied in order to obtain different doping levels. Crystalline structure of CdS:Er layers was cubic zincblende for all the doped-layers prepared. The (111) interplanar distance changes in irregular way with the $\mathrm{Er}$ doping level. Consequently, the energy band gap $\left(E_{g}\right)$ firstly increases and afterward diminishes becoming, at last, approximately constant at around $\mathrm{E}_{\mathrm{g}}=2.37 \mathrm{eV}$. For higher doping levels, in as-grown films, dark electrical conductivity $(\sigma)$ values reach about $1.8 \times 10^{-2} \Omega^{-1} \mathrm{~cm}^{-1}$ at room temperature. Logarithm of $\sigma$ versus $1 / \mathrm{kT}$ curves, where $\mathrm{k}$ is the Boltzmann's constant and $\mathrm{T}$ the absolute temperature, indicate an effective doping of $\mathrm{CdS}$ as a result of the $\mathrm{Er}$ introduction into the lattice of the material. Thermoelectric power measurements reveal an $n$-type doping with $1.1 \times 10^{18} \mathrm{~cm}^{-3}$ as maximum carrier density.

Transition from $\mathrm{CdS}$ to $\mathrm{CdCO}_{3}$ by deposition temperature influence [11]. Thin films of cadmium carbonate $\left(\mathrm{CdCO}_{3}\right)$ and cadmium sulfide $(\mathrm{CdS})$ were grown onto glass, substrates by means of the chemical bath (CB) method. The temperature of the bath $\left(\mathrm{T}_{\mathrm{d}}\right)$ was selected in the interval $23-80{ }^{\circ} \mathrm{C}$. At low temperatures, $\mathrm{CdCO}_{3}$ is the compound predominant in the layers. At high temperatures $\mathrm{CdS}$ is the compound deposited on the substrate. At intermediate $\mathrm{T}_{\mathrm{d}}$-values a mixture of both materials are present, i.e., the gradual transition from an insulator $\left(\mathrm{CdCO}_{3}\right)$ to a semiconductor $(\mathrm{CdS})$ growth occurs when $\mathrm{Td}$ increases. Physical properties of films were studied by means of X-ray diffraction, and optical absorption. The forbidden energy band gap of direct transitions $\left(\mathrm{E}_{\mathrm{g}}\right)$ was calculated by applying the $\alpha^{2} \sim\left(h v-\mathrm{E}_{\mathrm{g}}\right)$ relation to the optical absorption spectra.

Analysis of reactions in the transition from semiconducting $\mathrm{CdS}$ to insulating $\mathrm{CdCO}_{3}$ in form of thin films obtained by CBD (in Spanish) [12]. By Chemical Bath was obtained thin films on glass-substrates with temperature interval of $80^{\circ} \mathrm{C}-20^{\circ} \mathrm{C}$. The used solution are: $\mathrm{CdCl}_{2} 0.02 \mathrm{M}, \mathrm{KOH} 1.5 \mathrm{M}, \mathrm{NH}_{4} \mathrm{OH} 0.5 \mathrm{M}$ and $\mathrm{SC}\left(\mathrm{NH}_{2}\right)_{2}$ $0.2 \mathrm{M}$, they were prepared at room temperature using deionized water. Volume of reagents, velocity of agitation and reaction temperature stayed constant. The $\mathrm{pH}$ of reaction was approximately 8.3. The deposit time varies with temperature. From previous results on Optic Absorption, is obtained the prohibited bandwidth, for $\mathrm{CdS}$ at $80^{\circ} \mathrm{C}, \mathrm{E}_{\mathrm{g}}=$ $2.42 \mathrm{eV}$ and $\mathrm{CdCO}_{3}$ at $20{ }^{\circ} \mathrm{C}, \mathrm{E}_{\mathrm{g}}=3.87 \mathrm{eV}$. By X-ray diffraction was identified the cubic phase of $\mathrm{CdS}$ at $80^{\circ} \mathrm{C}$, with a peak located in the angular position: $2 \theta=[26.68]$ and at $20^{\circ} \mathrm{C}$ it observed signals at $2 \theta=[23.26,30.22,36.30,43.8$, 49.90] that correspond to $\mathrm{CdCO}_{3}$ in rombohedral phase. In interval $40^{\circ} \mathrm{C} \leq \mathrm{T} \leq 60^{\circ} \mathrm{C}$, was identified signal from both compounds. By Optic Microscopy was obtained pictures that shown the gradual transition of $\mathrm{CdS} \rightarrow \mathrm{CdCO}_{3}$ with growth of crystal. The precursors of ions sulphur $\left(\mathrm{S}^{-2}\right)$ and carbonate $\left(\mathrm{CO}_{3}{ }^{-2}\right)$ are sulphydric acid $\left(\mathrm{H}_{2} \mathrm{~S}\right)$ and carbonic acid $\left(\mathrm{H}_{2} \mathrm{CO}_{3}\right)$, respectively, in according this work. Both acids come from of hydrolytic decomposition of thiourea. The influence of $\mathrm{pH}$, solubility of $\left(\mathrm{H}_{2} \mathrm{~S}\right)$ and $\mathrm{CO}_{2}$ are considered in the interval of temperature deposited, and the influence of last in the reaction.

Au doping of CdS polycrystalline films prepared by cosputtering of CdS-Cd-Au targets [13]. Au doped CdS polycrystalline films were grown on Corning glass substrates at room temperature by co-sputtering from a $\mathrm{CdS}-\mathrm{Cd}-\mathrm{Au}$ target. Elemental $\mathrm{Cd}$ and $\mathrm{Au}$ were placed onto the $\mathrm{CdS}$ target covering small areas. The electrical, structural, and optical 
properties were analyzed as a function of $\mathrm{Au}$ content. The $\mathrm{Au}$ doped $\mathrm{CdS}$ polycrystalline films showed a p-type semiconductor nature. It was found that the electrical resistivity drops and the carrier concentration increases as a consequence of $\mathrm{Au}$ incorporation within the $\mathrm{CdS}$ lattice. In both cases, the changes were of several orders of magnitude.

Growth of $\mathrm{CdO}$ films from $\mathrm{CdO}_{2}$ films by chemical bath deposition: Influence of the concentration of cadmium precursor [14]. Cadmium peroxide films were grown by chemical bath deposition on glass slides at $50{ }^{\circ} \mathrm{C}$ using $\mathrm{CdCl}_{2}$ as cadmium source. Films were deposited at different nominal cadmium concentrations. As-grown films were annealed in air at $300{ }^{\circ} \mathrm{C}$ for obtaining cadmium oxide thin films. The structural, morphological, optical and compositional properties of $\mathrm{CdO}$ films were analyzed in terms of the cadmium nominal composition and the annealing effect.

\section{Hard Coatings}

Influence of substrate temperature on the hardness of ( $\mathrm{Ti}, \mathrm{Al}) \mathrm{N}$ films prepared by reactive radiofrequency cosputtering (in Spanish) [15]. By using the reactive magnetron radiofrequency co-sputtering technique and a $\mathrm{Ti}$ target partially covered with a small $\mathrm{Al}$ plate, $(\mathrm{Ti}, \mathrm{Al}) \mathrm{N}$ coatings were made on $\mathrm{c}-\mathrm{Si}$ in a reactive atmosphere of nitrogen and argon. Coatings were deposited at temperature room and at $150{ }^{\circ} \mathrm{C}$ as substrate temperature. Substrate temperature notably affected the thickness, crystalline grain size and hardness of the coatings. EDS results showed a higher aluminum content in the coatings for the samples growth at lower substrate temperature. X-ray diffraction measurements allowed us analyze the dependence of both structure and crystalline grain size on substrate temperature and composition of coatings. Scanning electron microscopy measurements showed a clear pyramidal microstructure of (Ti,Al)N coatings growth at room temperature, while growing at $150{ }^{\circ} \mathrm{C}$ of substrate temperature the microstructure is not well defined. Vickers hardness measurements were performed for all the samples.

\section{Tortilla Process}

Study of drying process in a halogene nixtamalized maize grains drier (in Spanish) [16]. Fitting the asymptotic model to experimental data of the dehydration process of processed corn grain at $50{ }^{\circ} \mathrm{C}$ in a moisture analyzer model HR83 Mettler-Toledo. The prepared corn grain samples with alkaline cooking of $0.8 \% \mathrm{Ca}(\mathrm{OH})_{2}$ at $92{ }^{\circ} \mathrm{C}$ with and without steeping time in its cooked water at times $0,2,4,6$, and $8 \mathrm{~h}$. The asymptotic equation is properly fitted to the experimental data, which allowed calculate the rate of hydration versus time by using its first derivative. We found that the hydration rate decreases rapidly with increasing drying time.

\section{Acknowledgements}

Thanks to Diana García Sotelo for her help with the processing of this information. As well as Miguel MeléndezLira and Martín Zapata-Torres for their useful comments.

\section{References}

[1]. O. Alvarez Fregoso, F. Sánchez Sinencio, J.G. Mendoza Alvarez, O. Zelaya, M. Farias, L. Cota Araiza, Superficies y vacío $\underline{1,77(1989) \text {. }}$

[2]. F.J. Espinoza-Beltrán, F. Sánchez-Sinencio, O. Zelaya-Angel, J.G. Mendoza-Alvarez, C. Vázquez-López, C. Alejo Armenta, M. Farías, L. Cota Araiza, Superficies y vacío 2, 22 (1990).

[3]. R. Ramírez Bon. F J. Espinoza-Beltrán, H. Arizpe Chávez, F. Sánchez Sinencio, O. Zelaya Angel, Superficies y vacío 2, 94 (1990).

[4]. R. Lozada, P. del Angel, O. Guzmán, G. Torres-Delgado, O. Zelaya, J.L. Martínez, Superficies y vacío 4, 45 (1992).

[5]. C.D. Gutiérrez, P.J. Mendoza, O. Zelaya-Angel, M.E. Rodríguez, Superficies y vacío 7, 82 (1997).

[6]. H. Arizpe-Chávez, R. Ramírez-Bon, F.J. Espinoza-Beltrán, O Zelaya-Angel, Superficies y vacío 8, 120 (1999).

[7]. J. Huerta, M. López, O. Zelaya, Superficies y Vacio 8, 125 (1999).

[8]. J. Huerta, M. López-López, O. Zelaya-Angel, Superficies y vacío 9, 22 (1999).

[9]. M. Becerril, O. Zelaya-Angel, J. R. Vargas-García, R. RamírezBon, Superficies y vacío 11, 47 (2000).

[10]. M. Rubín-Falfán, R. Lozada-Morales, J. A. Rivera-Márquez, M. R. Palomino-Merino, O. Portillo-Moreno, J. A. Dávila-Pintle, O. Zelaya-Angel, Superficies y vacío 13, 130 (2001).

[11]. O. Portillo-Moreno, H. Lima-Lima, R. Lozada-Morales, R. Palomino-Merino, A. B. Soto, O. Zelaya-Angel, Superficies y vacío 15, 19 (2002).

[12]. H. Lima-Lima, O. Portillo-Moreno, L.M. Espinosa Montes de Oca, R. Lozada Morales, O. Zelaya-Ángel, Superficies y vacío 21. 21 (2008).

[13]. M. Becerril, H. Silva-López, O. Zelaya-Angel, J.R. VargasGarcia, Superficies y vacío 25, 214 (2012).

[14]. E. Campos-Gonzalez, A. Guillén-Cervantes, J. SantoyoSalazar, O. Zelaya-Ángel, L.E. Ramírez-Velázquez, J. SantosCruz, S.A. Mayén-Hernández, F. de Moure-Flores, M. de la L. Olvera, G. Contreras-Puente, Superficies y vacío 28, 25 (2015).

[15]. L. García-González, F.J. Espinoza-Beltrán, J. MoralesHernández, O. Zelaya-Ángel, Superficies y vacío 14, 38 (2002).

[16]. J.L. Fernandez-Muñoz, M.A. Gruintal-Santos, O. ZelayaÁngel, H. E. Martínez-Flores, Superficies y vacío 26, 139 (2013).

(C) 2021 by the authors; licensee SMCTSM, Mexico. This article is an open access article distributed under the terms and conditions of the Creative Commons Attribution license (http://creativecommons.org/licenses/by/4.0/). 